\title{
On Textile Poetry in Textile Social History in Qin and Han Dynasties
}

\author{
Chunguang Ren $^{1} \&$ Xiaoming Yang ${ }^{1}$ \\ ${ }^{1}$ College of Humanities, Donghua University, Songjiang, Shanghai, China \\ Correspondence: Xiaoming Yang, College of Humanities, Donghua University, Songjiang, Shanghai, 201620, \\ China. E-mail: ynide@sina.com
}

Received: March 11, 2020

doi:10.5539/ass.v16n4p65
Accepted: March 29, $2020 \quad$ Online Published: March 30, 2020

URL: https://doi.org/10.5539/ass.v16n4p65

\begin{abstract}
This paper begins with the textile poetry of the Qin and Han dynasties. Using the method of mutual proof of poetic history, as far as possible from the textile production, textile technology, textile trade and textile culture to outline a complete clue of the history of the textile society in the Qin and Han dynasties. Trying to clarify the changes of textile culture and costume system in ancient China and to explore the relationship between textile production and social-economic development.
\end{abstract}

Keywords: $\mathrm{Han} F u$, Qin and Han dynasties, Textile Poetry, Textile Culture, Costume Culture

From book of songs to Chu Ci, Han Fu and poems in the Tang Dynasty, Song iambic verse and Yuan drama, through the poetry of dynasties, we can clearly see Chinese poets' insight into development of social economy and people's livelihood, as well as their patriotic feelings.

The Qin and Han dynasties were a period of social and cultural transformation in China. After the Warring States Period of the beacon fire smoke, writers absorbed the Warring States Period of prose and Chu Ci writing techniques, developed a new poetry genre in the history of Chinese literature - $\mathrm{Han} \mathrm{Fu}$. We find that in the poems written by writers in the Qin and Han dynasties, there are a lot of textile production techniques and textile trade, as well as a wealth of social and folk culture information. These textile poems are a treasure house for the study of the social history of textile in the Qin and Han dynasties.

\section{Qin and Han Textile Poetry and Society}

The cultivation and textile production of mulberry and flax in the Qin and Han dynasties were closely related to the high attention of the ruling class. In the pre-Qin period, the rulers of the past dynasties regarded heavy agriculture as a way to enrich country and strengthen army. The Han Dynasty was the earliest dynasty in the history of Chinese agriculture to raise mulberry production to the same status as agricultural production. It can be seen from Han Fu that textile production and foreign trade in the Han Dynasty were important pillars of economy.

\subsection{Han Fu Origin}

$\mathrm{Han} \mathrm{Fu}$, as the most representative literary genre in ancient Chinese literature, pays attention to literary talent and rhythm. It is characterized by both prose and poetry. emergence of a new literary genre has its social background, either because of the customs of the time, or from the evolution of ancient literary genre (Wang, 1934). $F u$, originally a writing technique, comes from one of the six arts of the book of songs. $F u$ gradually evolved into style in the Han Dynasty, and the two Han dynasties were the most prosperous period for the development of $F u$ as a style. As a literary genre, $F u$ had been produced as early as the pre-Qin period. Due to the influence of $C h u c i$ and the Warring States prose, $F u$ in the Han Dynasty merged the characteristics of poetry in the pre-Qin period and gradually formed the form of half poetry and half prose.

The early Western Han Dynasty was a development period of $\mathrm{Han} \mathrm{Fu}$, because of influence of $\mathrm{Chu}$ ci leaving the style of poetry, the writing technique of $\mathrm{Han} \mathrm{Fu}$ at this time is exaggerated, length is longer, representing literary temperament. The middle period in the Han Dynasty was the peak period of Han Fu. At this time, Han Fu was of great length, mostly describing the scenery of Kyoto in the Han Dynasty and eulogizing the prestige in the Han Dynasty. The late Han Dynasty was the transition period of Han Fu. At this time, Han Fu was short in length, lyrical in scenery, fresh in artistic conception and strong in rhythm. It reflected return of the style in the late Han Dynasty to the pre-Qin period. Han Fu contains rich contents of ancient Chinese textile science and 
technology. These poems are the direct historical data of development of textile industry and new direction of research on the development of textile technology and society in the Han Dynasty.

\subsection{Planting and Distribution of Mulberry and Hemp in Qin and Han Dynasties}

The planting of mulberry and hemp in the Qin and Han dynasties was mainly concentrated in the Yellow River basin and the Yangtze river basin. Yellow River basin mainly planted hemp, and mulberry. The Yangtze river basin was mainly planted mulberry, but also hemp crops. Compared with the Yangtze river basin, the Yellow River basin had a wider distribution of hemp crops. The formation of these two textile crop production areas is mainly due to differences in mountain and river landforms and climatic environment.

The Yellow River basin has a mild and dry climate with long sunshine hours. The habit of hemp plants is light loving, the soil environment and climate conditions in the Yellow River basin are especially suitable for the growth of hemp crops. In $X i D u F u$ ( $f u$ on the west capital), Ban Gu described scene of west capital Chang' an (now Xi' an), where the grain bore full seeds and the mulberry forest and hemp fields flourished. Jia Sixie, an outstanding agronomist in the Northern Wei Dynasty, described in detail the cultivation of hemp crops in the middle and lower reaches of the Yellow River in his works Qi Min Yao Shu (On Agriculture Technology for General People), from the above works, it can be seen that the production of hemp crops was very prosperous in Guanzhong area during the Qin and Han dynasties.

The cultivation of mulberry and hemp in the Yangtze river basin was mainly distributed in the areas of Bashu (now Sichuan Province) and the southern region of Yangtze river in Jiangsu and Zhejian, was suitable for planting ramie. Especially the Bashu region was wet and rainy climate, suitable for mulberry growth. In Shu Du $F u$ ( $F u$ on Capital of Shu Country), Yang Xiong described developed textile industry in Chengdu in the Han Dynasty. In the Southern and Northern dynasties, the writer Ren Fang once described the flourishing situation of mulberry planting in the Yangtze river basin in his poems (Yang, 2011).

\subsection{Textile Social Culture of Han Dynasty}

Mulberry and hemp were widely planted in the Han Dynasty, and there were many kinds of hemp and silk fabrics. The silks were colorful and of exquisite quality. With the opening of the silk road, the fine silk fabrics were sold to other countries in the western regions, which made the textile economy prosperous in the Han Dynasty. The hemp fabric is soft and fine in texture and cheap in quality. In the Han Dynasty, the clothes of the common people were mostly made of linen. The extravagant price of silk goods determined that only the upper ruling class could use it. The civilians have no right to wear silk, even if economic conditions permit. The common people had to meet the requirements of the dress and apparel system in order to be allowed to wear clothes made of silk in their old age.

\section{Textile Technology of Han Dynasty from Perspective of $\mathrm{Han} \mathrm{Fu}$}

The Han Dynasty was the peak period for the development of textile technology in ancient China. Around the origin of textile materials, the Han Dynasty formed several important textile production centers such as Shandong, Sichuan and Henan. The Western Han Dynasty capital Chang' an and Qilu Linzi (now Zibo in Shandong province) was the national silk trading center. Flourishing textile trade promoted the rapid improvement of the craft level of silk and hemp products and wool textilesy. Developed silk weaving industry promoted the wide range of textile tools such as reeling, spinning wheels and foot - tilting looms.

According to the records of $X i$ jing $Z a J u$ (The Notes on West Capital), in the early years of the Western Han dynasty, the wife of Chen Baoguang, a giant deer man, invented the polyhedry-polystealthy-jacquard machine to improve the jacquard craft process. She improved the traditional flat heald jacquard process into bunched heald jacquard, which greatly improved the efficiency of brocade. At that time, the silk she made could not be bought by the average man for a thousand taels of gold.

The structure of the jacquard machine invented by Chen Baoguang's wife can only be inferred from surviving stone portraits in the Han dynasty. According to the description of $J i F u F u$ ( $F u$ on Weaving Women) written by Wang Yi in the Eastern Han Dynasty, the jacquard machine in the Han Dynasty had a combination of fuselage and installation system, which basically had the main components of traditional jacquard machine in China (Lu, 1992).

\section{Analyze Textile Economy in the Han Dynasty from $\mathrm{Han} \mathbf{F u}$}

\subsection{Textile Production in the Han Dynasty}

In the Han Dynasty, agriculture and silk weaving were the main sources of its social economy, and also the means to stabilize the society and meet the political demand. As a result of the improvement of textile tools and 
textile technology, increased productivity, accelerated the development of the textile industry, promote the prosperity of textile trade. Zhang Qian's exploration of the western regions marked the beginning of the flourishing textile economy in the Han dynasty.

In the Western Han Dynasty, the government attached great importance to the economy of silk industry, and set up a large scale official organization in Linzi and Xiangyi, with thousands of weavers. Linzi, once the capital of $Q i$, is famous for its light and delicate fabrics. Xiangyi in the central plains area is famous for its rich brocade. Wang chong's treatise on balance records the production areas of silk in the Han Dynasty. Linzi was rich in textile industry, almost every woman can engage in silk production Xiangyi has the custom of brocade, clumsy women can become skillful (Shi \& Wang, 2004).

In the Eastern Han Dynasty, the textile production area was gradually pushed from north to south. Sericulture reeling technology has been widely promoted in the south of the Yangtze river, silk industry on the rigin southern Yangtze river gradually developed. The southwest Bashu area, because of its production of Shu brocade exquisite workmanship, gorgeous colors and exquisite patterns and popular. Chengdu area of Sichuan province has gradually become an important silk production center. In the period of Shu Han, Zhuge Liang issued a decree to persuade farmers and mulberry, now the people are poor, the national strength is weak, the military resources of the war with the enemy, only rely on the production of brocade. At that time, the silk industry in Chengdu was extremely developed. With a large number of government-run and privately-run enterprises and an amazing output of silk, it occupied the main market of domestic silk trade and was sold to western countries through the silk road. Chengdu is also known as Jinguancheng because of the popularity of Shu brocade, tributary of the Minjiang river that runs around the city is called the Jinjiang river, market where Shu brocade is bought and sold is called Jinshi, place where the weavers lived was called Jinli. It can be seen that Shu brocade trade flourished in Chengdu area during the Three Kingdoms period in the Han Dynasty.

\subsection{Textiles in the Han Dynasty}

There are many kinds of textiles in the Han Dynasty, most of which are reflected in $\mathrm{Han} \mathrm{Fu}$. The first aid written by Shi You, a calligrapher, was a primer for children's literacy in the Han Dynasty, more than 50 kinds of silk are recorded in it. The textile content recorded in it has clearly described silk fabric, according to the fabric structure, pattern, color, processing technology into four categories (Shi \& Wang, 2004). Shi You's article not only praised the superb skill level of the silk weaving industry, but also reflected the prosperity of the silk weaving industry. It shows that the prosperity of textile culture is high, and textile production has been integrated into every aspect of people's daily life.

In 1972, the archaeological excavation of the Han tomb in Mawangdui, Changsha, Hunan province, unearthed a variety of high-grade silk fabrics of the Han dynasty. These Han Dynasty silk fabrics are fine in texture, bright in color, exquisite in weaving texture, and there are patterns such as rindling pattern, rectangle pattern, bird pattern, peacock pattern, flower pattern and so on. One of the most archaeological shock is that Mawangdui no. 1 tomb unearthed a piece of plain gauze clothing, its weight only $10.2 \sim 11.3$ grams, with the modern advanced textile technology can't recover. Many Han Dynasty silk fabrics unearthed from the Han tomb at Mawangdui not only show the world the advanced textile technology of China's Han Dynasty, but also confirm the super high level of silk weaving in Changsha.

\section{Costume Culture in $\mathrm{Han} \mathrm{Fu}$}

In the early Han Dynasty, hundreds of wastes were waiting for prosperity, economy withered, and materials were scarce. Therefore, the Western Han Dynasty did not set strict rules on clothing. The early Han Dynasty inherited the Qin Dynasty's costume system from its shape to its color. It was not until the eastern Han Dynasty that the dress system of the Han Dynasty was gradually completed. Dong Zhongshu in his works that in the Spring and Autumn period Fanlu put forward that according to the status level of the Han Dynasty clothing system, which to some extent realized the distinction between noble and cheap. Even if ordinary people become rich, they cannot forget their humble origins, nor can they wear the wrong clothes, nor can they overstep their manners by being rich (Ren, 2017). As a master of Confucianism in the Western Han Dynasty, Dong Zhongshu's idea of rejecting other schools of thought and respecting Confucianism was adopted by emperor Wudi in the Han Dynasty. After burning books and burying Confucian scholars in the Qin Dynasty, Confucianism became the official guiding ideology in the Han Dynasty and the ritual system ushered in a comprehensive revival. It not only restricts the ordinary people's daily life, but also directly interferes with the dress of all classes. The clothing system in the Han Dynasty put forward by Dong Zhongshu was influenced by the ritual system of Zhou Dynasty. The costumes of the Western Han Dynasty continued the tradition in the Qin Dynasty, while the costumes in the Qin Dynasty integrated the characteristics of the Warring States period costumes, which were more influenced by the 
deep clothing of the state of Chu. In the early Han Dynasty, many of them came from the former state of Chu. So Han clothing not only has the shadow of Chu clothing, even the culture in the early Han Dynasty is also influenced by $\mathrm{Chu} C \mathrm{C}$.

In the early period of the Western Han Dynasty, the color of clothing was red to show the dignity of the status. In the period of emperor Wudi in the Han Dynasty, the color of clothing advocated yellow. Later, yellow was gradually agreed to be the special color for the clothing of the yellow emperor. Due to the influence of the deep clothing of the state of Chu, the clothes in the Han Dynasty were very exquisite in shape and structure, and the clothes were always embroidered, which was extremely luxurious. Although there is no special chapter about costumes in $\mathrm{Han} \mathrm{Fu}$, there are many depictions related to costumes because of its complicated content. According to $\mathrm{Han} \mathrm{Fu}$, the emperor's clothing in the Han Dynasty had twelve patterns of embroidery, and the regalia was decorated with jade, seal and sword.

\section{Silk Road Culture and Textile Trade from Perspective of $\mathbf{H a n} \mathbf{F u}$}

The Han Dynasty was the first dynasty in ancient China to establish trade relations with the western regions. As a conventional geographical name, the western regions first appeared in the historical records of Sima Qian. 'It was the year old Han sent hussars to defeat tens of thousands of Hsiung-nu in the western regions to the Qilian mountains' (Sima, 2006). In 138 BC, emperor Wudi in the Han Dynasty sent Zhang Qian on an envoy to the western regions to seek a military alliance to attack Hsiung-nu. However, Zhang Qian inadvertently promoted the textile culture and economic and trade exchanges between east and west, and opened the economic and trade road from the central plains to the western regions and connected the Eurasian continent. Zhang Qian's route to the western regions is the Silk Road first proposed by German geography Richthofen. From this beginning, China's fine silk fabrics and superb textile skills, as well as advanced craftsmanship and culture spread from central Asia to Europe. Western textile technology and art are gradually absorbed and integrated by the east (Zhou, 2017).

The opening of the Silk Road promoted the economic and trade prosperity and development of the regions along the Silk Road. It has deepened the textile trade and cultural exchanges between China and the west. It promoted friendly political and people-to-people exchanges between the Han Dynasty and the countries in the west regions. It can be seen from the names of the western regions and various exotic foreign objects appearing constantly in $\mathrm{Han} \mathrm{Fu}$ that in the Han Dynasty, the countries in the western regions had close economic and cultural exchanges with the central plains. In the period of Wei, Jin and the Southern and Northern Dynasties, the patterns and patterns of beads and rare birds and animals from the western regions, as well as the figures of exotic cultures appeared on the unearthed textiles. This shows that the western culture began to spread to the central plains and gradually affected the production and life of the central plains people.

The strange customs and goods of the western regions recorded in $\mathrm{Han} F u$ fully illustrate the prosperity of the textile economy and the frequent foreign economic and trade exchanges in the Han Dynasty. The silk road promoted the high prosperity in the Han Dynasty's textile economy. The textiles of Han Dynasty were popular in many countries in the western regions. It shows the superb textile technology in ancient China and the sericulture civilization with a long history.

According to the records by Sima Qian, Zhang Qian was in the country of Da Xia when he saw bamboo sticks and cloth produced in the Ba Shu area. Zhang Qian asked people of Da Xia, where did these things come from. People of Da Xia said that traders from the Han Dynasty brought them to Indian markets (Sima, 2006). After the Silk Road was opened, the Western Han Dynasty's economic development increased rapidly. At that time, the Han Dynasty engaged in agricultural work did not make money as quickly as the craftsmen, while the craftsmen did not make as much profit as the merchants. Although spinning and embroidering profit also can, but after all still be inferior to open a shop to come money fast. Although businessmen are low in social status, they can make money to get rid of poor lives.

The flourishing commerce via the Silk Road increased the wealth of Han society and improved the quality of life of its people. At that time, Chang 'an, the capital of the Han Dynasty, was the most prosperous city in the world, with a highly developed social economy and prosperous villages and towns. Goods from five prosperous textile centers are gathered here and sold in the western regions and throughout the country. In Shu Du fu, Yang Xiong described the busy commercial scene in Chengdu. The four sides of the merchants gathered in the land of Shu, the market noisy, everywhere was the voice of the peddlers one after another. The construction of water conservancy projects in the Han Dynasty facilitated the transportation of goods by land and water. While the commerce and trade in the western regions were flourishing, the commercial busyness of the maritime Silk Road was no less than that of the land route. The production of silkworm mulberry in the Qin and Han dynasties was 
the beginning of China's ancient textile economy. According to the records of $\mathrm{Han} F u$, the highly developed textile business in the Han Dynasty led to the prosperity of social economy. Economic and trade exchanges via the silk road not only enhanced the cultural exchanges between China and the West, but also opened the integration of Chinese and the people of the West.

\section{Conclusion and Suggestions}

The different costumes of different dynasties and different nationalities in different stages are the reflection of the social thought and culture at that time. Due to the limited economic conditions and the restrictions of official institutions on the use of clothing and fabrics, the common people in the Han Dynasty had a single style of clothing. Ordinary people can only wear clothes, only in old age can wear silk clothes with additional conditions. Because of the unique style of $\mathrm{Han} \mathrm{Fu}$, it is mainly aimed at the class of dignitaries and literati. Therefore, the costumes described in $\mathrm{Han} \mathrm{Fu}$ are representative, which can reflect the costume culture and popular aesthetics of the Han mainstream society. The description of costumes in $\mathrm{Han} \mathrm{Fu}$ is the direct historical data to study the development and inheritance of costumes in the Han Dynasty. It is of great significance to the study of costume culture in a dynasty.

The textile production in the Han Dynasty was based on individual families and small-scale private ownership of producers, which was a self-sufficient small-scale peasant economy. Small producers can not only satisfy the daily life of the family, but also trade the surplus goods in the family production. The rulers of the Han Dynasty fixed the family life pattern of men ploughing and women weaving by law and policy. Small-scale peasant economy became the template of family life in ancient China and was inherited by subsequent dynasties. It was the implementation of the policy of combining agriculture and mulberry cultivation by the rulers that pushed textile economic development to the peak in the Han Dynasty. With Zhang Qian's exploration of the western regions, silk from the central plains was continuously exported to central Asia and introduced to Europe, creating the world-renowned textile economy of the silk road.

\section{References}

Ren, H. L.(2017). A Study on The Phenomenon of Strange Costume in Ancient China (p. 43). Nanchang: Jiangxi People's Publishing House.

Shi, Y., \& Wang, M. C. (2004a). Analysis of textile poetry in past dynasties (p. 14). Beijing: China Literature and History Press.

Shi, Y., \& Wang, M. C. (2004b). Analysis of textile poetry in past dynasties (p. 16). Beijing: China Literature and History Press.

Sima, Q. (2006). Records of the Historian (p. 586). Xi'an: Taibai Literature and Art Publishing House.

Sima, Q. (2006). Records of the Historian (p. 587). Xi'an: Taibai Literature and Art Publishing House.

Wang, F. (1934). The formation and characteristics of Han Hu and Six Dynasties Ci Fu. Academic Style, 4(2), 33-81.

Yang, S. (2011). Ren fang and aspirations of celebrities in the Southern dynasty (p. 371). Shanghai: Shanghai Ancient Books Publishing House.

Zhou, Q. C., Zhao, F., \& Bao, M. X. (2017). General history of Chinese textile (p. 271). Shanghai: Donghua University Press.

\section{Copyrights}

Copyright for this article is retained by the author(s), with first publication rights granted to the journal.

This is an open-access article distributed under the terms and conditions of the Creative Commons Attribution license (http://creativecommons.org/licenses/by/4.0/). 